\title{
Long Term Benefits of Post-surgical Adjuvant Radiotherapy Among Sub-population of Patients with Stage IB Grade 2 Endometrial Cancer
}

\author{
Mihriban KOCAK ${ }^{1}$, Makbule EREN ${ }^{1}$, Murat M. NAKI ${ }^{2}$, Atınç AKSU ${ }^{1}$, Hasniye CELIK ${ }^{2}$, \\ Alper OZKAN ${ }^{1}$, Alparslan MAYADAGLI' ${ }^{1}$, Orhan UNAL ${ }^{2}$ \\ ${ }^{1}$ Dr. Lutfi Kirdar Kartal Training and Research Hospital, Department of Radiology Oncology \\ ${ }^{2}$ Dr. Lutfi Kirdar Kartal Research and Training Hospital, Department of Obstetrics and Gynecology, Istanbul, TURKEY
}

\begin{abstract}
Present study was designed to evaluate potential risks and benefits of adjuvant radiotherapy in selected patients with intermediate-risk endometrial cancer. A total of 100 patients with stage IB grade II endometrial cancer followed up in Radiation Oncology Clinic at Dr. Lutfi Kirdar Training and Research Hospital were evaluated retrospectively to determine the influence of postsurgical adjuvant radiotherapy on disease-free survival, local recurrences and locally-relaps free survival. Side effects related to adjuvant radiotherapy were also evaluated. Forty-seven (47\%) patients were determined to undergo total abdominal hysterectomy + bilateral salphingo-oopherectomy and 53 (53\%) patients, total abdominal hysterectomy + bilateral salphingo-oopherectomy + pelvic lymph node dissection. Postsurgical adjuvant radiotherapy was administered in 77 patients (77\%), while the surgery was the sole medical intervention for 23 patients (23\%). The median follow-up period was 40.5 months (range: 6-139) Five-year disease-free survival (96.6\% vs. $80.5 \%$; $p<0.01$ ) and local control $(98.6 \%$ vs. $80.5 \%$; $\mathrm{p}<0.05$ ) were better in patients who were administered postoperative radiotherapy compared to patients without postoperative radiotherapy.

In conclusion, while our results concerning homogenous sub-population of patients with stage IB grade II endometrial cancer seem to support the use of postoperative adjuvant radiotherapy, larger and more detailed prospective studies are required for determination of its exact prognostic value.
\end{abstract}

Keywords: endometrial cancer stage IB, Adjuvant radiotherapy, Overall survival

\section{ÖZET}

Post-operatif Adjuvan Radyoterapinin Stage IB Grade 2 Endometrium Kanseri Hasta Popülasyonunda Uzun Dönem Faydaları

Bu çalışma orta risk endometrium kanserli hasta populasyonunda adjuvant radyoterapinin potansiyel risk ve yararlarını değerlendirmek amacıyla tasarlandı.

Stage IB grade II endometrium kanseri tanısıyla Dr. Lutfi Kırdar Eğitim ve Araştırma Hastanesi Radyasyon Onkolojisi Kliniğinde izlenmekte olan toplam 100 hastada postoperatif adjuvant radyoterapinin hastalıksız sağ kalım, lokal rekürrens ve lokal kontrol oranlarına etkisi retrospektif olarak belirlendi. Adjuvan radyoterapiye yönelik yan etkiler de ayrıca değerlendirildi. 
Toplam 47 (\%47) hastada total abdominal histerektomi+bilateral salfingo-ooferektomi ve 53(53\%) hastada ise total abdominal histerektomi+bilateral salfingo-ooferektomi+ pelvik lenf nodu diseksiyonu uygulandığı saptandı. Postoperatif adjuvan radyoterapi 77 (\%77) hastada, cerrahi ise 23 (\%23) hastada başlıca tedavi yöntemi olup, medyan izlem süresi 40.5 ay (6-139) olarak bulundu. Hastalıksız 5 ylllık sağkalım (\%96.6 ila \%80.5; p< 0.01) ve lokal kontrol (\%98.6 ila \%80.5; p< 0.05) oranlarının postoperatif radyoterapi uygulanan hastalarda uygulanmayanlara göre belirgin şekilde daha yüksek olduğu bulundu. Sonuç olarak, stage IB grade II endometrium kanseri hastalarından oluşan homojen bir populasyonuna yönelik olan bulgularımız, bu hastalarda postoperatif adjuvant radyoterapi kullanımı destekler nitelikte görünse de, postoperatif adjuvant radyoterapinin gerçek prognostik değerinin anlaşılabilmesi için daha geniş ölçekli ve daha kapsamlı çalışmalara gereksinim vardır.

Anahtar Kelimeler: Stage IB endometrium kanseri, Adjuvan radyoterapi, Genel sağkalım

\section{INTRODUCTION}

Endometrial cancer is the most common gynecologic malignancy diagnosed in the western countries. Over $75 \%$ of these cancers are classified according to staging of the International Federation of Gynecology and Obstetrics (FIGO) I-II with favorable prognostic factors. ${ }^{1}$ However, a subgroup of patients with early-stage disease will have cancers characterized by pathological features that considerably increase the risk of both locoregional and distant relapse. This intermediate risk category has been defined as lesions that invade the myometrium (stage IB/IC) or cervix (stage IIA/IIB). ${ }^{2}$

The standard treatment for patients with stage I endometrial cancer is surgery, consisting of peritoneal lavage for cytology, extra-fascial total abdominal hysterectomy and bilateral salpingo-oophorectomy (TAH+BSO) and dissection of pelvic and aortic nodes. ${ }^{3}$

Intraoperative inspection and palpation of abdominal organs, including the diaphragm, liver, omentum, and pelvic and bowel peritoneal surfaces together with the pathological results form the optimal basis of future adjuvant therapy. ${ }^{3}$

Recommendation for adjuvant therapy is determined by risk factors that affect local recurrence and death rates, such as stage, myometrial invasion degree, grade, lymphovascular invasion and patient age. ${ }^{4}$ The National Comprehensive Cancer Network (NCCN) Practice Guidelines for Endometrial Cancer version 2000 recommended observation, vaginal brachytherapy (VBT), or pelvic RT with or without VBT as adjuvant therapy for patients with stage IA grade 3 , stage IB grade 2 , and stage IC grade 1 cancer. $^{5}$
However, the value of postoperative RT in the treatment of patients with stage I endometrial carcinoma is controversial due to a lack of data from randomized studies and the low relapse rate. ${ }^{3}$ According to a systematic review and meta-analysis of 1770 patients from four randomised trials ${ }^{6}$ as well as data from the ASTEC/EN. ${ }^{5}$ radiotherapy trial ${ }^{7}$, adjuvant radiotherapy results in a small reduction in risk of isolated women with intermediate-risk and high-risk early-stage endometrial cancer. ${ }^{8}$ Although adjuvant radiotherapy causes a decrease in local recurrences, no advantage on general survival rates has been shown. Post-operative policy is still ambiguous, especially in some selected sub-group patients, such as medium-risk Stage IB, grade II patients. ${ }^{3}$

Since the requirement of post-operative adjuvant radiotherapy among patients with stage I endometrial cancer is still a subject of debate, we aimed to present data on use of postoperative radiotherapy in endometrial carcinoma by evaluating potential risks and benefits of adjuvant radiotherapy in selected patients with intermediate-risk surgical stage IB grade II endometrial cancer.

\section{PATIENTS AND METHODS}

A total of 100 patients [median age (range) was 58 (33-82) years] with stage IB grade II endometrial cancer who were followed up in Radiation Oncology Clinic at Dr. Lutfi Kirdar Training and Research Hospital between 1998 and 2008 were included in the present study. Retrospective analysis of hospital records were performed concerning comparison of surgery plus adjuvant radiotherapy and surgery per se groups in terms of disease-free survival rates, local recurrences and locally-relapse 
free survival. Side effects related to adjuvant radiotherapy were also evaluated and graded according to the 'National Cancer Institute' (NCI) and the 'Common Toxicity Criteria' (CTC). ${ }^{9}$

Pathological slides were evaluated by a senior pathologist who recorded in detail all pathological parameters, including histological subtype, cellular grade, tumor size, and evidence of lymphatic invasion. All patients were staged based on the $1988 \mathrm{In}$ ternational Federation of Gynecology and Obstetrics (FIGO) system..$^{10}$ In patients lacking pelvic lymph node dissection (PLND) as a component of surgical operation, staging was accomplished via the depth of myometrial invasion as well as total abdominal MRI confirming lack of extra-uterine disease. Cases with papillary serous or clear cell histology in their pathological examinations were not included in the study.

Fifty cases received intracavitary radiotherapy alone at a total dose of $30 \mathrm{~Gy}$ in 5 fractions, 11 cases received pelvic radiotherapy alone at a total dose of 46-50 Gy over five weeks, and the other $16 \mathrm{ca}-$ ses received intracavitary RT at a total dose of 20 Gy in 3 fractions after application of 46 Gy pelvic radiotherapy. External radiotherapy was administered in conventional doses via a four-field box or 3D-CRT technique, using a $15 \mathrm{MV}$ medical linear accelerator (GE Saturn 41- Siemens Oncor-Varian Clinax). It was planned so that during radiotherapy the PVT would encompass the pelvic lymph nodes by a $2 \mathrm{~cm}$ margin. Intracavitary radiotherapy doses were identified within depth of $0.5 \mathrm{~cm}$ from the vaginal area. Dosage was applied using the "Target II treatment planning system" and measuring the rectum and bladder doses of each patient. Intracavitary treatment was given by afterloading unit of the type Curitron with Cs-137 sources.

Statistical Analysis: The analysis of survival rates was conducted via the Kaplan-Meier method. Time to progression was determined as the time from surgery to recurrence, metastases or, death due to other reasons without recurrence; general survival was determined as time lapsed from diagnosis till death. Local-relapse free survival was defined as the time from surgery to local recurrence or last follow up time. Survival curves were compared using the Log rank test. The Cox proportional hazard model was

\begin{tabular}{|c|c|c|}
\hline & $\mathbf{n}$ & $\%$ \\
\hline \multicolumn{3}{|l|}{ Age (years) } \\
\hline Median (min-max) & \multicolumn{2}{|c|}{58 (33-82) } \\
\hline$<60$ years & 64 & 64 \\
\hline$>60$ years & 36 & 36 \\
\hline \multicolumn{3}{|l|}{ Surgical operation } \\
\hline $\mathrm{TAH}+\mathrm{BSO}$ & 47 & 47 \\
\hline $\mathrm{TAH}+\mathrm{BSO}+\mathrm{PLND}$ & 53 & 53 \\
\hline \multicolumn{3}{|c|}{ Lymphovascular invasion } \\
\hline Present & 16 & 16 \\
\hline Absent & 65 & 65 \\
\hline Unknown & 19 & 19 \\
\hline \multicolumn{3}{|l|}{ Adjuvant radiotherapy } \\
\hline Absent & 23 & 23 \\
\hline Pelvic RT & 11 & 11 \\
\hline Pelvic RT+IC & 16 & 16 \\
\hline IC & 50 & 50 \\
\hline \multicolumn{3}{|c|}{$\begin{array}{l}\text { Median duration (min-max) } 40.5 \text { (6-139) } \\
\text { of follow up (months) }\end{array}$} \\
\hline
\end{tabular}

used to analyze the effects of several variables on survival. The comparison of different clinicopathological characteristics were done using the Chi-square test.

\section{RESULTS}

According to patient demographics and clinical features summarized in Table 1, median age (minmax) was determined as 58 (33-82) years. A total of $64(64 \%)$ patients were at or younger than 60 years while $36(36 \%)$ patients were older than 60 years. According to hospital records, surgical operation was total abdominal histerectomy (TAH)+bilateral salphingo-oopherectomy (BSO) in 47\% $(n=47)$ of patients while $53(53 \%)$ patients had underwent $\mathrm{TAH}+\mathrm{BSO}+$ Pelvic lymph node dissection 
Table 2. Route of postoperative radiotherapy application with respect to surgical treatment

\begin{tabular}{|llll|}
\hline & TAH+BSO (n= 47) & TAH+BSO+PLND (n= 53) & Total \\
\hline Postoperative radiotherapy & $35(45.5)$ & $42(54.5)$ & $77(100.0)$ \\
External & $5(6.5)$ & $6(7.8)$ & $11(14.3)$ \\
Intracavitary & $20(25.9)$ & $30(38.9)$ & $50(64.9)$ \\
External + Intracavitary & $10(12.9)$ & $6(7.8)$ & $16(20.8)$ \\
\hline
\end{tabular}

BSO: bilateral salphingo-oopherectomy; PLND: pelvic \pm para-aortic lymphadenectomy; RT: radiotherapy;

TAH: total abdominal hysterectomy

(PLND). Lymphovascular invasion was present in $16 \%$ of patients. Postoperative adjuvant radiotherapy was performed in 77 patients $(77 \%)$ including pelvic radiotherapy $(11 \%$; at a total dose of $46-50$ Gy over five weeks), pelvic radiotherapy + intracavitary radiotherapy $(16 \%$; pelvic radiotherapy in a dose of 46 Gy was followed by intracavitay radiotherapy at a dose of $20 \mathrm{~Gy}$ in 3 fractions) and IC alone (50\%; at a total dose of $30 \mathrm{~Gy}$ in 5 fractions). On the other hand, surgery was the sole medical intervention for 23 patients (23\%). The median followup period was 40.5 months (range: 6-139) at the end of which all patients were still alive (Table 1).

Postoperative radiotherapy was administered in $45.5 \%$ and $54.5 \%$ of patients with $\mathrm{TAH}+\mathrm{BSO}$ and TAH+BSO+PLND operations, respectively. Route of postoperative radiotherapy application with res- pect to surgical treatment is given in Table 2 .

Throughout the follow-up, local recurrence was observed in a total of $6(6 \%)$ patients among which patients with postoperative radiotherapy composed $33.3 \%(n=2)$. Vaginal \pm pelvic recurrence developed in 4 patients $(66.6 \%)$, distant metastasis occured in a single patient (16.6\%), and combined vaginal and distant metastasis developed in 1 patient (16.6\%). In 4 (17.3\%) of 23 patients patients without postoperative radiotherapy, local recurrence was detected in 3rd, 4th, 8th and 18th months. However local recurrence was observed only in one patient (1.2\%) among 77 patients with postoperative radiotherapy in the 8th month of follow up. Data concerning local recurrence among patients are summarized in Table 3.

Table 3. Clinical features related to patients with local recurrence of the malignancy

\begin{tabular}{|c|c|c|c|c|c|c|c|}
\hline $\begin{array}{l}\text { Patient } \\
\text { no }\end{array}$ & $\begin{array}{l}\text { Age } \\
\text { (year) }\end{array}$ & Surgical operation & Radiotherapy & LVI & $\begin{array}{l}\text { Latency } \\
\text { (mo) }\end{array}$ & Territory & $\begin{array}{l}\text { Duration of } \\
\text { follow up (mo) }\end{array}$ \\
\hline 1 & 60 & $\mathrm{TAH}+\mathrm{BSO}$ & Pelvic RT + IC & Unknown & 31 & Lung, paraaortic & 139 \\
\hline 2 & 55 & TAH+BSO+PLND & None & Unknown & 4 & $\begin{array}{l}\text { Vaginal, paraaortic, } \\
\text { mediastinum }\end{array}$ & 14 \\
\hline 3 & 56 & $\mathrm{TAH}+\mathrm{BSO}$ & IC & None & 8 & Vaginal, pelvic & 48 \\
\hline 4 & 61 & $\mathrm{TAH}+\mathrm{BSO}$ & & & & & \\
\hline & None & None & 3 & Vaginal & 7 & & \\
\hline 5 & 54 & $\mathrm{TAH}+\mathrm{BSO}$ & & & & & \\
\hline & None & Unknown & 8 & Vaginal & 23 & & \\
\hline 6 & 75 & $\mathrm{TAH}+\mathrm{BSO}+\mathrm{PLND}$ & None & None & 18 & Vaginal & 96 \\
\hline
\end{tabular}




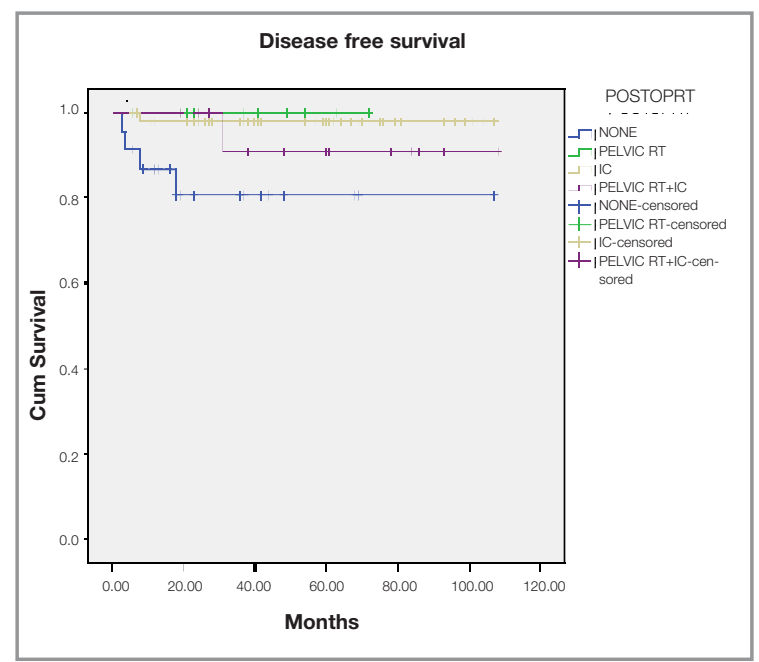

Figure 1. Disease free survival rate in patients with or without postoperative radiotherapy

Significant improvement in median disease-free survival time in patients with postoperative radiotherapy [105 months $(95 \% \mathrm{Cl}$ : 101-109)], when compared to patients without postoperative radiotherapy [87.9 months (95\% Cl: 71-104.9)] $(p<0.01)$.

Overall rates for 1, 2, 3 and 5-year disease-free survival were $95.9 \%, 94.8 \%, 93.2 \%$ and $93.2 \%$ in the population, respectively. Median disease-free survival time was significantly longer in patients with postoperative radiotherapy [105 months (95\% CI: 101-109)], when compared to patients without postoperative radiotherapy [87.9 months (95\% CI: 71104.9)] ( $<<0.01$; Figure 1). Five-year disease-free survival rates $(96.6 \%$ vs $80.5 \%$; $p<0.01)$ were bet-

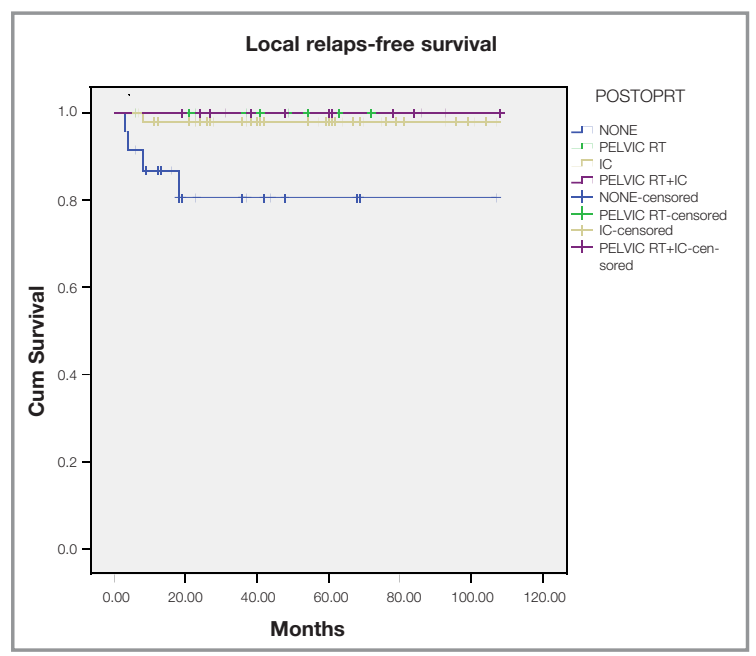

Figure 2. Relapse-free local survival rate in patients with or without postoperative radiotherapy

Significant reduction in local relapse-free survival in patients with postoperative radiotherapy [106 months (\%95 Cl: 104-109)], when compared to patients without postoperative radiotherapy [87.9 months (95\% Cl: 71-104.9)] $(\mathrm{p}<0.001)$.

ter in patients with postoperative radiotherapy when compared to patients without postoperative radiotherapy (Table 4). Five-year disease-free survival rates obtained among patients with endometrial cancer were signifcantly higher in case of pelvic radiotherapy when compared to pelvic + intracavitary radiotherapy and intracavitary radiotherapy alone groups ( $\mathrm{p}<0.05$ for each; Table 3$)$.

Table 4. Comparison of disease free survival rates (\%) in patients with or without postoperative adjuvant radiotherapy

\begin{tabular}{|c|c|c|c|c|c|}
\hline & & \multicolumn{4}{|c|}{ Disease free survival rates (\%) } \\
\hline & & 1st year & 2nd year & 3rd year & 5 th year \\
\hline \multicolumn{6}{|c|}{ Postoperative adjuvant radiotherapy } \\
\hline & Overall & $98.6^{*}$ & $98.6^{*}$ & $96.6^{\star}$ & $96.6^{\star}$ \\
\hline \multirow[t]{3}{*}{ Yes $(n=77)$} & Pelvic RT & 100 & 100 & 100 & 100 \\
\hline & Pelvic RT and IC & 100 & 100 & $90.9^{* *}$ & $90.9^{\star *}$ \\
\hline & IC alone & $97.9^{\star \star}$ & $97.9^{\star \star}$ & $97.9^{\star \star}$ & $97.9^{\star \star}$ \\
\hline No $(n=23)$ & 86.7 & 80.5 & 80.5 & 80.5 & \\
\hline \multicolumn{6}{|c|}{$\begin{array}{l}\text { RT: radiotherapy; IC: intracavitary } \\
{ }^{\star} p<0.01 \text { compared to survival rates in patients without postoperative radiotherapy } \\
{ }^{* \star} p<0.05 \text { compared to pelvic radiotherapy }\end{array}$} \\
\hline
\end{tabular}


Table 5. Comparison of locally-relapse free survival (\%) in patients with or without postoperative adjuvant radiotherapy

\begin{tabular}{|c|c|c|c|c|c|}
\hline & & \multicolumn{4}{|c|}{ Locally-relapse free survival (\%) } \\
\hline & & 1st year & 2nd year & 3rd year & 5th year \\
\hline \multicolumn{6}{|c|}{ Postoperative adjuvant radiotherapy } \\
\hline \multirow[t]{4}{*}{ Yes $(n=77)$} & Overall & $98.6^{*}$ & $98.6^{*}$ & $98.6^{*}$ & $98.6^{\star}$ \\
\hline & Pelvic RT & $100+$ & $100+$ & $100+$ & $100+$ \\
\hline & Pelvic RT and IC & $100+$ & $100+$ & $100+$ & $100+$ \\
\hline & IC alone & 97.9 & 97.9 & 97.9 & 97.9 \\
\hline No $(n=23)$ & & 86.7 & 80.5 & 80.5 & 80.5 \\
\hline $\begin{array}{l}R T \text { : radiother } \\
{ }^{*} p<0.05 \text { com } \\
+p<0.05 \text { com }\end{array}$ & $\begin{array}{l}\text { tracavitary. } \\
\text { survival rates in pati } \\
\text { intracavitary radioth }\end{array}$ & $\begin{array}{l}\text { thout post } \\
\text { lone. }\end{array}$ & diotherapy. & & \\
\hline
\end{tabular}

Table 6. Acute toxicities related to postoperative adjuvant radiotherapy

\begin{tabular}{|lll|}
\hline & $\mathbf{n}$ & $\%$ \\
\hline Grade 1-2 urinar irritation & 9 & 11.7 \\
Grade 1-2 diarrhea & 5 & 6.5 \\
Grade 2-3 rectitis & 2 & 2.6 \\
Mucosal changes in the vagina & 11 & 14.3 \\
& & \\
\hline
\end{tabular}

Overall 1, 2 and 5-year locally-relapse free survival were $95.9 \%, 94.8 \%$ and $94.8 \%$ in the population, respectively. Median local relapse-free survival was significantly longer in patients with postoperative radiotherapy [106 months (\%95 CI: 104-109)], when compared to patients without postoperative radiotherapy [87.9 months (95\% CI: 71-104.9)] $(\mathrm{p}<0.001$; Figure 2). Five-year locally-relapse free survival $(98.6 \%$ vs $80.5 \%$; $<<0.05)$ was better in patients with postoperative radiotherapy when compared to patients without postoperative radiotherapy (Table 5). Five-year locally-relapse free survival observed among patients with endometrial cancer was significantly lower in intracavitary radiotherapy alone-group when compared to pelvic radiotherapy and pelvic + intracavitary radiotherapy groups ( $\mathrm{p}<0.05$ for each; Table 5).
Toxicity assessment revealed that 18 (23.4\%) of 77 patients treated with postoperative radiotherapy experienced acute side-effects (Table 6). External radiotherapy was associated with acute side effects in 4 patients including urinary disorder $(n=1)$, diarrhea $(n=2)$ and vaginal stenosis $(n=1)$. Six of acute toxic events were related to intracavitary radiotherapy including urinary disorder $(n=2)$, vaginal stenosis $(n=3)$ and urinary disorder + vaginal stenosis $(n=1)$. External + intracavitary radiotherapy was associated with toxic side effects in 8 patients including urinary disorder $(n=3)$, vaginal stenosis $(n=$ 3 ) and urinary disorder + vaginal stenosis $(n=2)$.

When chronic side effects were evaluated, it was noted that of 5 chronic side effects, 1 was related to external radiotherapy (diarrhea), 1 was related to intracavitary radiotherapy (vaginal stenosis) and 3 were related to external + intracavitary radiotherapy including chronic vaginal stenosis $(n=2)$ and rectitis necessitating transverse loop colostomy $(n=$ 1). There were no recurrences.

Univariate analysis revealed that while prognostic value of radiotherapy was shown via its significant association with better local-relapse free survival $(\mathrm{p}=0.013)$, disease- free survival $(\mathrm{p}=0.05)$ and overall survival $(p=0.026)$, there was no relation between presence of lymphovascular invasion, type of surgery and age. Multivariate analysis revealed no statistically significant difference for factors. 


\section{DISCUSSION}

Endometrial cancer is confined to the uterine corpus for $75 \%$ of cases at the time of diagnosis and uncorrected survival rates of greater than $75 \%$ are expected among these patients. ${ }^{11}$ However, an intermediate risk category has been defined as lesions that invade the myometrium (stage IB/IC) or cervix (stage IIA/IIB) are characterized by pathological features that considerably increase the risk of both loco-regional and distant relapse. ${ }^{2}$ While treatment modality for low risk, high intermediate risk and high risk endometrial cancers have gained clarity, adjuvant whole pelvic radiotherapy for patients with intermediate-risk endometrial cancer (IA G3, IB G2) is still being endorsed., 2,12

Recent data from two prospective randomized clinical trials show a reduction in recurrence rates by adjuvant whole pelvic radiotherapy following total abdominal hysterectomy and bilateral salpingooophorectomy (TAH-BSO) with or without lymph node sampling. However, neither of these trials demonstrated that adjuvant pelvic radiotherapy improved overall survival. ${ }^{12,13}$

In the multicenteric, prospective, randomized Postoperative Radiation Therapy in Endometrial Carcinoma (PORTEC) study $^{13}$, adjuvant radiotherapy in patients with "stage I" endometrial cancer was reported to reduce local recurrence but had no impact on overall survival. The GOG 99 trial $^{12}$ concerning role of adjuvant whole pelvic radiotherapy in women with stages IB, IC, and IIA endometrial cancer following TAH-BSO reported that adjuvant radiotherapy significantly reduced the risk of locoregional recurrence without a significant difference in overall survival. In another study conducted with 540 women with endometrial stage I cancer who had received postoperative vaginal radiotherapy ${ }^{14}$, although pelvic radiotherapy reduced vaginal and pelvic recurrence ( $2 \%$ vs $7 \%$ ), more distant metastases were found in the pelvic radiotherapy group (10\% vs 5\%), and 5-year survival was not improved $(89 \%$ vs $91 \%)$.

In contrast to published lack of an evidence concerning survival advantage related to postoperative radiotherapy in endometrial stage I cancer ${ }^{3,12-14}$, the effect of postoperative radiotherapy on 5-year survival and locally-relapse free survival were significant in our study. Therefore our finding of better 5- year survival and locally-relapse free survival obtained among our patients with postoperative adjuvant radiotherapy in terms of overall as well as radiotherapy-specific results seem remarkable in this manner.

In fact, overall local recurrence rates obtained in the present study including a homogenous population of patients with stage IB grade 2 endometrial cancer were much lower than the literature which was $13-19 \%$ for populations composed of stage IC G1-2, IB G3 endometrial cancer. ${ }^{12,15}$ Adjuvant RT treatment was reported to reduce the local failure rate from $14.7 \%$ to $6.6 \%$ in deep invasion and from $20 \%$ to $4.4 \%$ in cases with high-grade tumors (G3) and deep invasion (14). Similar results were also reported from PORTEC study. ${ }^{16}$ Similar to consistent data on reduction in local recurrence rates for deep invasive and high grade endometrial tumors, patients with postoperative radiotherapy enclosed only $2 \%$ of overall local recurrence. Lower local recurrence rates obtained among our patients with post operative radiotherapy was better than $2.6 \%$ $4.4 \%$ recurrence rates reported to occur within first 2 years among patients with stage I endometrial carcinoma..$^{3,17-19}$ Also recurrence rates in our patients without postoperative radiotherapy (4\%) was lower than the literature. ${ }^{12,15}$ Lack of significantly better locoregional control achieved with pelvic radiotherapy in the previous studies has been explained in part because of the small sample size and partly because many cases were excluded from those studies. ${ }^{3}$ In our opinion, inconsistency in results of studies addressing the need for adjuvant radiotherapy in intermediate risk (IA G3, IB G2) endometrial cancers may be attributable to heterogenity of subject populations composed of not only IA G3 or IB G2 patients but also low grade as well as high grade patients in these studies..$^{12,15,20,21}$ Therefore, including a homogenous population composed of only stage IB grade 2 endometrial cancer patients seems to have a role in these results.

Interestingly, recent decisions of the FIGO Committee to declassify some properties of staging are presumably based on prognostic considerations that former IA and IB stages are elected to merge upon identification of common favorable prognosis for these sub-stages. Furthermore, Committee merged the former Stage IIA with Stage I disease due to the 
ambiguity of defining cervical invasion which has been based on the involvement of the cervical mucosa only. ${ }^{22}$ Time will show the ultimate influence of this new staging system on improvements in the quality and consistency of patient care, and the quality of research in endometrial cancer. ${ }^{22}$

Among 4 patients without postoperative radiotherapy who experienced local recurrence, first patient had lung metastasis in the 31 st month and para-aortic lymph node metastasis in the 120th month and has been living for 139 months upon almost full response to hormonotherapy (Megestrole Acetate). Hormonotherapy with external pelvic and IC radiotherapy treatment was started for the second patient who experienced local recurrences in the 4th month alongside para-aortic and mediastinal lymph node metastasis and the third patient who admitted to the healthcare unit with both local recurrence and pelvic lymph node metastasis in the 8th month. Both patients, who experienced local recurrences and distant metastasis, are still alive in the 14th and 48th months without any disease progression. The fourth, fifth and sixth patients experienced only local recurrences. These patients are being followedup after receiving external and IC radiotherapy. The patients are alive and disease-free in the 7th, 23rd and 96th months.

Concerning prognostic factors determining local recurrence in endometrial cancers, no relation between disease progression and other variables including age of the patient, presence of lymphovascular invasion, and the type of past surgery in our study was in line with the literature reporting lack of a link between factors such as age $(<60$ years, $\geq$ 60 years), tumor size $(<2 \mathrm{~cm}, \geq 2 \mathrm{~cm}$ ), parity (nulliparous or multiparous), lymphovascular invasion, diabetes mellitus and obesity and the prognosis of endometrial cancer. ${ }^{3}$ On the other hand we have determined a significant positive relation of adjuvant RT to overall disease prognosis among our patients.

Late toxicity in patients receiving adjuvant radiotherapy seriously affects quality of life the patients. In the GOG study (12) G1-2 toxicity was $63 \%$ and G3-4 toxicity was 5\%. In PORTEC I study ${ }^{13}$, 5-year late toxicity in all grades has been detected as $26 \%$, while serious complications were seen in $3 \%$ of the patients. Although adjuvant radiotherapy reduces the risk of loco-regional recurrence as the present study, external beam radiotherapy carries an inherent risk of damage and toxicity and should be avoided in stage I endometrial cancer patients with no high risk factors (patients with grade 1 to 2 and stage Ia to b) since they have a low recurrence rate $^{6}$ In our study, 5 (6.5\%) patients experienced vaginal stenosis and $1(1.2 \%)$ patient underwent a colostomy due to rectitis.

In conclusion retrospective analysis of data concerning utility of post-operative adjuvant radiotherapy has revealed a significant improvement in 5-year local recurrence as well as survival rates of patients with intermediate-risk endometrial cancer. While better survival and diminished local relaps in our homogenous sub-population of patients with stage IB grade 2 endometrial cancer seems to be related to efficacy and safety of postoperative adjuvant radiotherapy, the need for larger scaled prospective studies is obvious to clarify its real prognostic value.

\section{REFERENCES}

1. Martinez-Monge R, Nagore G, Cambeiro M, et al. Intravaginal 1-week high-dose-rate brachytherapy alone for Stages I-II endometrial cancer. Brachytherapy 6: 195-200, 2007.

2. Rankins NC, Secord AA, Jewell E, et al. Cost-effectiveness of adjuvant radiotherapy in intermediate risk endometrial cancer. Gynecol Oncol 106: 388-393, 2007.

3. $\mathrm{Yu} \mathrm{H}$, Juang C, Huang $\mathrm{C}$, et al. Is Adjuvant Radiotherapy Effective in Intermediate-risk Surgical Stage I Endometrial Cancer? Taiwanese J Obstet Gynecol 43: 101-106, 2004.

4. DiSaia PJ, Creasman WT, Boronow RC, et al. Risk factors and recurrent patterns in Stage I endometrial cancer. Am J Obstet Gynecol 151: 1009-1015, 1985.

5. The National Comprehensive Cancer Network (NCCN) Practice Guidelines for Endometrial Cancer, version 2000. Available at: http://www.nccn.org/

6. Kong A, Simera I, Collingwood M, et al. Adjuvant radiotherapy for stage I endometrial cancer: systematic review and meta-analysis. Ann Oncol 18: 1595-604, 2007.

7. Blake P, Swart AM, Orton J, et al. Adjuvant external beam radiotherapy in the treatment of endometrial cancer (MRC ASTEC and NCIC CTG EN.5 randomised trials): Pooled trial results, systematic review, and meta-analysis. Lancet, 373: 97-99, 2009. 
8. Kitchener H, Swart AM, Qian Q, et al. Efficacy of systematic pelvic lymphadenectomy in endometrial cancer (MRC ASTEC trial): a randomised study. ASTEC study group. Lancet 373: 125-36, 2009.

9. National Cancer Institute. Common toxicity criteria (Version 2), Division of Cancer Treatment and Diagnosis, National Cancer Institute, USA: Bethesda, 1999.

10. Shepherd JH. Revised FIGO staging for gynaecological cancer. Br J Obstet Gynaecol 96: 889-892, 1989. Erratum in: Br J Obstet Gynaecol 99: 440, 1992.

11. Creutzberg CL, van Putten WL, Koper PC, et al. PORTEC Study Group. The Postoperative Radiation Therapy in Endometrial Carcinoma. The morbidity of treatment for patients with stage I endometrial cancer: results from a randomized trial. Int $\mathrm{J}$ Radiat Oncol Biol Phys 51: 1246-1255, 2001.

12. Keys HM, Roberts JA, Brunetto VL, et al. A phase III trial of surgery with or without adjunctive external pelvic radiation therapy in intermediate risk endometrial adenocarcinoma: a Gynecologic Oncology Group study. Gynecol Oncol 92: 744-751, 2004.

13. Creutzberg CL, van Putten WL, Koper PC, et al. Surgery and postoperative radiotherapy versus surgery alone for patients with stage- 1 endometrial carcinoma: multicentre randomised trial. PORTEC Study Group. Post Operative Radiation Therapy in Endometrial Carcinoma. Lancet 355: 1404-1411, 2000.

14. Aalders J, Abeler V, Kolstad P, et al. Postoperative external irradiation and prognostic parameters in stage I endometrial carcinoma: Clinical and histopathologic study of 540 patients. Obstet Gynecol 56: 419-427, 1980.

15. Creutzberg CL, van Putten WL, Koper PC, et al. PORTEC study group. Survival after relapse in patients with endometrial cancer: results from a randomized trial. Gynecol Oncol 89: 201-209, 2003.

16. Scholten AN, van Putten WL, Beerman $\mathrm{H}$, et al. PORTEC study group. Postoperative radiotherapy for stage I endometrial carcinoma: Long-term outcome of the randomized PORTEC trial with central pathology review. Int J Radiat Oncol Biol Phys 63: 834-838, 2005.
17. Ayhan A, Taskiran C, Celik C, et al. Is there a survival benefit to adjuvant radiotherapy in high-risk surgical stage I endometrial cancer? Gynecol Oncol 86: 259263, 2002.

18. Jolly $\mathrm{S}$, Vargas $\mathrm{CE}$, Kumar $\mathrm{T}$, et al. The impact of age on long-term outcome in patients with endometrial cancer treated with postoperative radiation. Gynecol Oncol 103: 87-93, 2006.

19. Morrow CP, Bundy BN, Kurman RJ, et al. Relationship between surgical-pathological risk factors and outcome in clinical stage I carcinoma of the endometrium: a Gynecologic Oncology Group study. Gynecol Oncol 40: 55-65, 1991.

20. Shaeffer DT, Randall ME. Adjuvant Radiotherapy in Endometrial Carcinoma. The Oncologist 10: 623-631, 2005.

21. Straughn JM Jr, Huh WK, Kelly FJ, et al. Conservative management of stage I endometrial carcinoma after surgical staging. Gynecol Oncol 84: 194-200, 2002.

22. Mariani A, Dowdy SC, Podratz KC. New surgical staging of endometrial cancer: 20 years later. Int J Gynaecol Obstet 105: 110-111, 2009.

\section{Correspondence}

Dr. Mehmet Murat NAKi

Cihat Saran Sok. Çagdas Apt. A Blok

No: $11 / 3$

34841 Küçükyalı

Maltepe, Istanbul / TURKEY

Tel: (+90.532) 7706666

Fax: (+90.216) 4415162

e-mail: mmuratnaki@yahoo.com 